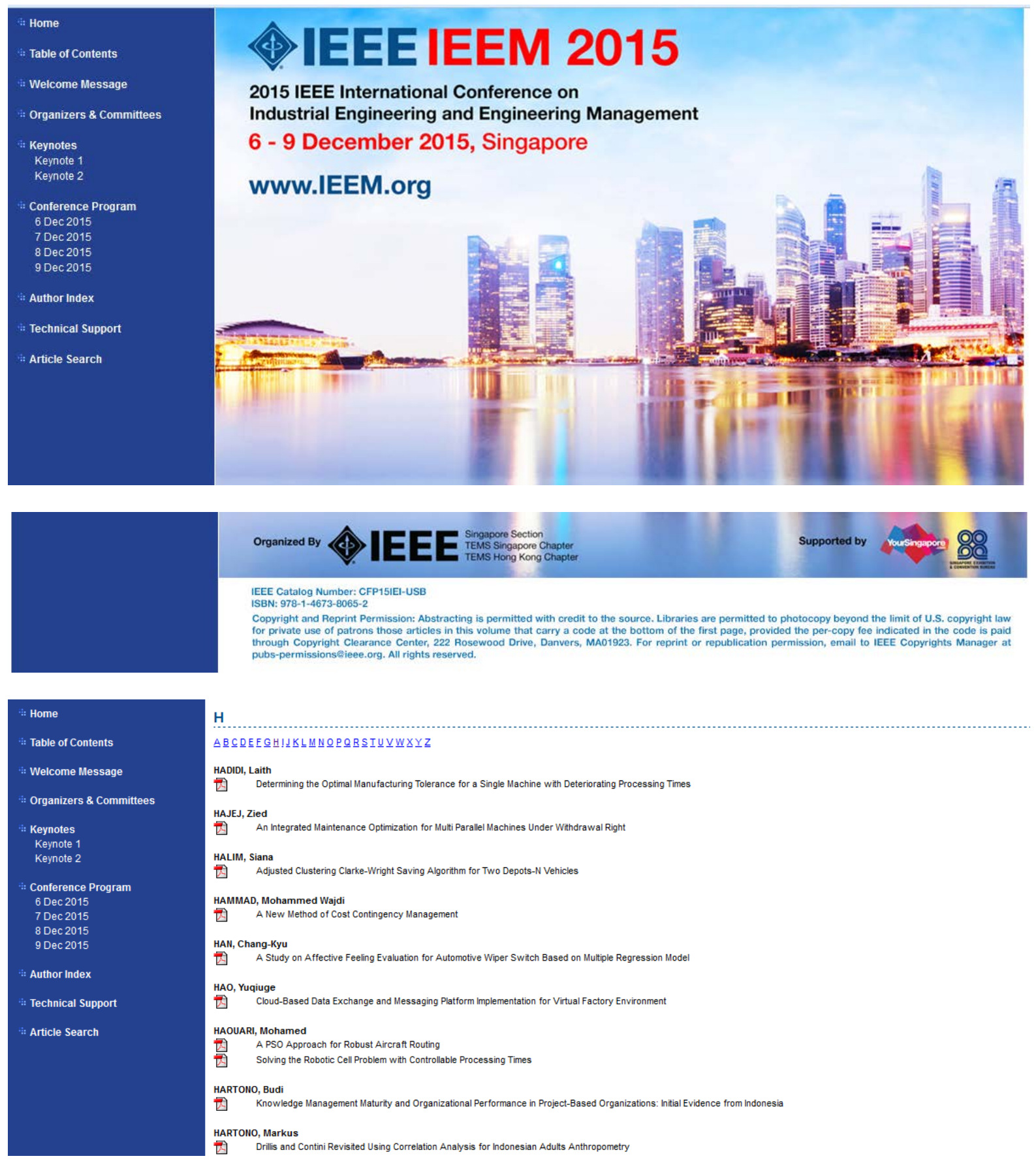




\title{
Drillis and Contini Revisited Using Correlation Analysis for Indonesian Adults Anthropometry
}

\author{
M. Hartono ${ }^{1}$, L. H. Gunawan ${ }^{1}$ \\ ${ }^{1}$ Department of Industrial Engineering, University of Surabaya, Surabaya, Indonesia \\ (markus@staff.ubaya.ac.id)
}

\begin{abstract}
Research on anthropometry, nowadays, becomes more essential and important due to the complexity of products, devices, equipment and systems for users. The most challenging part in anthropometry study is that the lack of sufficient valid, reliable and sustainable anthropometric data for certain nationalities. According to recent studies, an attempt to provide a comprehensive anthropometric measurement system has been conducted. Following to the previous study by Drillis and Contini, this study uses a similar methodology on how to predict any anthropometric measures through sufficient accuracy from a single measure of stature and weight, taken from 119 Indonesian adults. The expected contribution of this study is that to find which measures are significantly associated with stature and weight, respectively. It is of highly beneficial for product designers and any human-work system interactions.

Keywords-Anthropometry, Drillis and Contini, Indonesian adults, stature, weight
\end{abstract}

\section{INTRODUCTION}

Anthropometry is a critical aspect in human factors engineering (known as ergonomics) when it comes to the stage of designing product or work station. It is highly useful in obtaining effective design for high utilization and productivity. How to measure and collect sufficient anthropometric data is a big challenge. It is due to different method, cultural issue, gender, geographical factor and many other factors. The collection of anthropometric data has been done through a very simple method [1] to a sophisticated technology procedure [2]. Nevertheless, anthropometric data is still of highly needed. Lack of anthropometric involvement may lead to work-related injuries or stress.

Pheasant and Haslegrave [3] have shown convenient anthropometric measurement using boney tips and landmarks. This measurement has been adopted and modified in a study on anthropometric data of Indonesian and Singaporean populations [1]. Simpler anthropometric measurement yet accurate is of highly required.

Inherently, some anthropometric dimensions are deemed to be correlated. Any of those body dimensions can be predicted with sufficient accuracy from a single measure of standing body height or stature[4, 5]. A recent study showed that there were significant correlations among many measures from anthropometric data obtained [6]. Width and girth measures were intercorrelated and had more significant correlation with body weight. It is, however, a study on the modification of Drillis and Contini's measurement is relatively unexplored. Due to the needs of the use of updated anthropometric data, a more reliable and valid approach for measuring anthropometric data is highly required.

In fact, the Indonesian anthropometry is quiet limited. In national-based level, there are only 1000 data available, as provided in http://www.antropometriindonesia.org/. The most recent study about Indonesian anthropometry taking into account three different largest ethnic groups has been conducted [7]. Since Indonesia has more than 17,000 islands and 300 ethnic groups, updating representative anthropometric data becomes a huge challenge and highly potential. In addition, other factors such as different ages and data collection time are of critical.

The objective of this study is that to revisit the findings of previous similar studies $[3,4,6]$ by doing analysis on the correlations among many measures from data obtained in recent anthropometric study of Indonesian adults. It is expected that the results of this study will be utilized a set of guide to predict reliable and valid anthropometric measures.

\section{BRIEF LITERATURE REVIEW}

A. Anthropometry and work system design

Anthropometry means how to take into account user or human differences in terms of segmental body dimensions, genders, and races for product or system design. It is important since human can act as designer, customer or user. In work system design, it is called as user-centered design which involves the product, the user and the task. It is accordance with the ergonomics basic concept of how to fit the task to the human [8]. More specifically, anthropometric consideration for any work system design will increase work performance, efficiency and productivity, as well as decrease any accidents or work-related injuries.

\section{B. Drillis and Contini and ratio scaling method}

Basically, human body segment has a unique combination of muscle, fat, bone, and other parts/tissues. Moreover, the density within a given body segment is found to be non uniform. Limb segments are derived as a function of whole-body density [6]. By taking huge samples into consideration, some body segments are intercorrelated. Stature and weight are commonly used as the scaling dimension, in the way that they are used to predict other measures $[3,6]$. 